\title{
Cap-independent translation of encephalomyocarditis virus RNA: structural elements of the internal ribosomal entry site and involvement of a cellular 57-kD RNA-binding protein
}

\author{
Sung K. Jang1 and Eckard Wimmer \\ Department of Microbiology, State University of New York at Stony Brook, Stony Brook, New York 11794 USA
}

\begin{abstract}
Translation of encephalomyocarditis virus (EMCV) mRNA occurs by ribosomal internal entry into the 5'nontranslated region ( $5^{\prime}$ NTR) rather than by ribosomal scanning. The internal ribosomal entry site (IRES) in the EMCV 5' NTR was determined by in vitro translation with RNAs that were generated by in vitro transcription of EMCV cDNAs containing serial deletions from either the 5' or 3' end of the EMCV 5' NTR. Regions downstream of nucleotide 403 and upstream of nucleotide 811 of EMCV were required for efficient translation. Site-directed mutagenesis revealed that a stem-loop structure $(400$ nucleotides upstream of the initiation codon) was essential for IRES function. We discovered a $57-\mathrm{kD}$ cellular protein whose specific interaction with this stem-loop appears to be prerequisite for IRES function. A pyrimidine-rich stretch proximal to the initiation codon was also crucial for efficient translation of EMCV mRNA. We propose that ribosomes bind directly to the initiating AUG without scanning.
\end{abstract}

[Key Words: Internal ribosomal entry; RNA-binding protein; oligopyrimidines]

Received March 16, 1990; revised version accepted July 6, 1990.

Numerous observations regarding the structure and function of picornavirus mRNAs have suggested that the mechanism of synthesis of picornavirus proteins is exceptional (see, e.g., Lee et al. 1976; Wimmer 1982). Apart from the $5^{\prime}$ end, picornavirus genomic and mRNAs are identical molecules, and both are infectious in tissue-culture cells (Nomoto et al. 1977; Pettersson et al. 1977). The most striking feature of picornavirus mRNAs is that their $5^{\prime}$ terminus is pUp..., a property unique among mammalian mRNAs (Hewlett et al. 1976; Nomoto et al. 1976). Another unusual feature of picornavirus RNAs is that they have retained long (650-1200 nucleotides), 5'-nontranslated regions $\left(5^{\prime} \mathrm{NTRs}\right.$; compiled by Palmenberg 1987). This defies the notion that the NTRs of the viral RNAs should have evolved to be of minimal length because of the very high mutation rate in RNA virus replication and for reasons of genetic economy (Holland et al. 1982; Reanney 1984). The 5' NTRs of picornaviruses therefore may have been selected for their roles in viral proliferation such as efficient translation, RNA replication, and encapsidation of genomic RNAs. Moreover, the 5' NTRs contain many unused AUG codons, and all attempts to use the classical ribosome binding/nuclease protection assay of

${ }^{1}$ Corresponding author.
Steitz (1975) for the identification of the AUG that initiates polyprotein synthesis have failed (Dorner et al. 1982, and citations therein).

We recently studied the initiation of translation of mRNA of encephalomyocarditis virus (EMCV), a member of the genus Cardiovirus. We proposed that this process involves the binding of ribosomes to the $5^{\prime}$ NTR independently of a free $5^{\prime}$ end of the EMCV mRNA. More specifically, we presented evidence suggesting that before initiation of translation, the ribosomes attach to an internal ribosomal entry site, referred to as IRES, that is several hundred nucleotides long (Jang et al. 1988, 1989). These data explained results by Shih et al. (1987), who determined an important region for translation of EMCV mRNA by oligonucleotide hybrid-arrested translation. An element similar to the IRES of EMCV has also been identified in poliovirus RNA (Pelletier and Sonenberg 1988, 1989; Trono et al. 1988), and aphthovirus RNA (Kühn et al. 1990). The precise size of the IRES element of any picornavirus RNA, however, has not been described.

The 5' NTRs of Picornaviridae, a family of plus-strand RNA viruses, can be divided into two groups: one consisting of the genera Cardio- and Aphthovirus (the latter represented by foot-and-mouth disease virus, FMDV), and the other of the genera Enterovirus (represented by 
poliovirus) and Rhinovirus. The former differ from the latter in that they contain a stretch of poly $(\mathrm{C})$ within the $5^{\prime}$ NTR, $\sim 200$ nucleotides downstream from the $5^{\prime}$ end (Porter et al. 1974; Palmenberg et al. 1984). The function of this homopolymeric region, which can be as long as 600 residues (Brown 1979), is not well understood, but it is unlikely that $5^{\prime}$-terminal nucleotides up to and including the poly $(\mathrm{C})$ play a role in controlling translation (Sangar et al. 1980; Jang et al. 1988). On the basis of phylogenetic comparison, computer-aided folding, and biochemical studies, secondary structures within the $5^{\prime}$ NTRs of picornaviruses have been suggested (Rivera et al. 1988; Pilipenko et al. 1989a, 1989b; Skinner et al. 1989 ). With respect to these higher order structures, the $5^{\prime}$ NTRs can also be divided into two groups that coincide exactly with the two groups mentioned above. Remarkably, there is very little apparent resemblance between the secondary structures of the $5^{\prime}$ NTRs of cardioviruses and aphthoviruses, on the one hand, and those of enteroviruses and rhinoviruses on the other hand (Pilipenko et al. 1989a,b). An exciting possibility is that the IRES elements of different picornaviruses may control their tissue specificity by responding to different host cell factors (Svitkin et al. 1988).

We have now defined the borders of the IRES element of EMCV RNA, and we describe the binding of a cellular protein of unknown function to a specific stem-loop structure of the EMCV IRES. This interaction appears to be essential for IRES function in translation of EMCV RNA. The cellular protein and the binding to the viral RNA are distinct from those recently described for poliovirus RNA by Meerovitch et al. (1989).

The possibility of cellular mRNAs conferring cap-independent translation will be discussed in view of the recent observation that a specific cellular protein is translated in poliovirus-infected cells (Sarnow 1989).

\section{Results}

Determination of the $5^{\prime}$ border of the IRES element in EMCV 5' NTR

We have shown that the segment comprised of nucleotides 260-834 of the EMCV $5^{\prime}$ NTR /total length of the 5' NTR is 834 nucleotides; Pilipenko et al. 1989a; A.C. Palmenberg, pers. comm.) was sufficient to allow internal entry of ribosomes, as defined by the ability of dior polycistronic mRNAs to allow efficient translation of a downstream cistron in vivo and in vitro (Jang et al. 1988,1989 ). We also showed that truncation up to nucleotide 484 of EMCV (nucleotides 485-834), as well as more extensive $5^{\prime}$ deletions, nearly abolished the function of the IRES element. To determine the $5^{\prime}$ border of the IRES, several plasmids containing serial 5 ' deletions in the EMCV 5' NTR were constructed. To minimize initiation of translation by a scanning mechanism that could conceivably supersede IRES function when the latter was destroyed by deletion, we placed the modified EMCV 5' NTRs into a plasmid that, on transcription with T7 RNA polymerase, yielded dicistronic, uncapped
mRNA (see Fig. 1A; Jang et al. 1988). This dicistronic mRNA consisted, $5^{\prime}$ to $3^{\prime}$, of the poliovirus $5^{\prime}$ NTR, a reporter cistron (SEA, encoding a polypeptide of $38 \mathrm{kD}$ containing 10 methionine residues|, a segment of the EMCV 5' NTR, and the second reporter cistron ECAT (Fig. 1A; Jang et al. 1988, 1989). ECAT encodes CAT' (a polypeptide of $25 \mathrm{kD}$ containing 10 methionines) that consists of bacterial chloramphenicol acetyltransferase (CAT) plus 17 amino acids of the amino-terminal portion of the EMCV polyprotein (Jang et al. 1989) because initiation of the EMCV polyprotein occurs at the eleventh AUG of the EMCV 5' NTR (see Fig. 6; Palmenberg et al. 1984).

In vitro transcripts of the plasmids carrying deletions in the EMCV $5^{\prime}$ NTR were translated in rabbit reticulocyte lysate (RRL), a system in which the poliovirus 5' NTR functions poorly (Nicklin et al. 1987; Jang et al. 1988). The rationale for using the poliovirus $5^{\prime}$ NTR at the end of the dicistronic mRNAs was to avoid translation of the second cistron by readthrough of ribosomes from the first cistron (for discussion, see Jang et al. 1988, 1989). As can be seen in Figure 1B, all transcripts produced similar amounts of the $S E A$ polypeptide, an observation that served as an internal control for the translation. The amount of $\mathrm{CAT}^{\prime}$, on the other hand, varied with the different constructs.

RNA transcripts containing a deletion up to nucleotide 373 (MPS1-ECAT374) and up to nucleotide 392 (MPS1-ECAT393) of the EMCV 5' NTR showed about three- and fivefold reductions in translation of the following indicator gene (ECAT), respectively (Fig. 1B, cf. lane 1 with lanes 2 and 3). An explanation for this reduction will be offered in the Discussion. A construct deleted up to nucleotide 402 (MPS1-ECAT403M2), which contains a double mutation indicated by asterisks in Figure 1A, showed translation efficiency comparable to MPS1-ECAT393, a transcript with wild-type sequence of nucleotides 393-834 (cf. Fig. 1B, lane 3 with 4). Translation of the ECAT gene, on the other hand, was decreased 150 - and 300 -fold by deletions up to nucleotides 421 and 425 , respectively (Fig. 1B, lanes 5 and 6). The data indicate that the sequence downstream of nucleotide 403 is crucial for internal ribosomal entry. This region includes at its $5^{\prime}$ border a conserved stem-loop structure, as determined by Pilipenko et al. (1989a; stem-loop E in Fig. 6 , below). The deletion up to nucleotide 421 removed half of the stem-loop structure. Replacement of the deleted region with a heterologous sequence $(30$ nucleotides) failed to restore translation (Fig. 1A, MPS1ECAT426+; Fig. 1B, lane 6). This indicates that the primary and/or the secondary structure of the deleted region is crucial for efficient IRES function. The importance of the stem-loop structure in translation will be discussed later.

Using oligonucleotide-mediated hybrid arrest of translation, Shih et al. (1987) concluded that oligonucleotides hybridizing to nucleotides $420-449$ or to sequences upstream thereof had minimal effects on translation of EMCV mRNA. On the other hand, oligonucleotides hybridizing to nucleotides $450-479$ or to sequences down- 


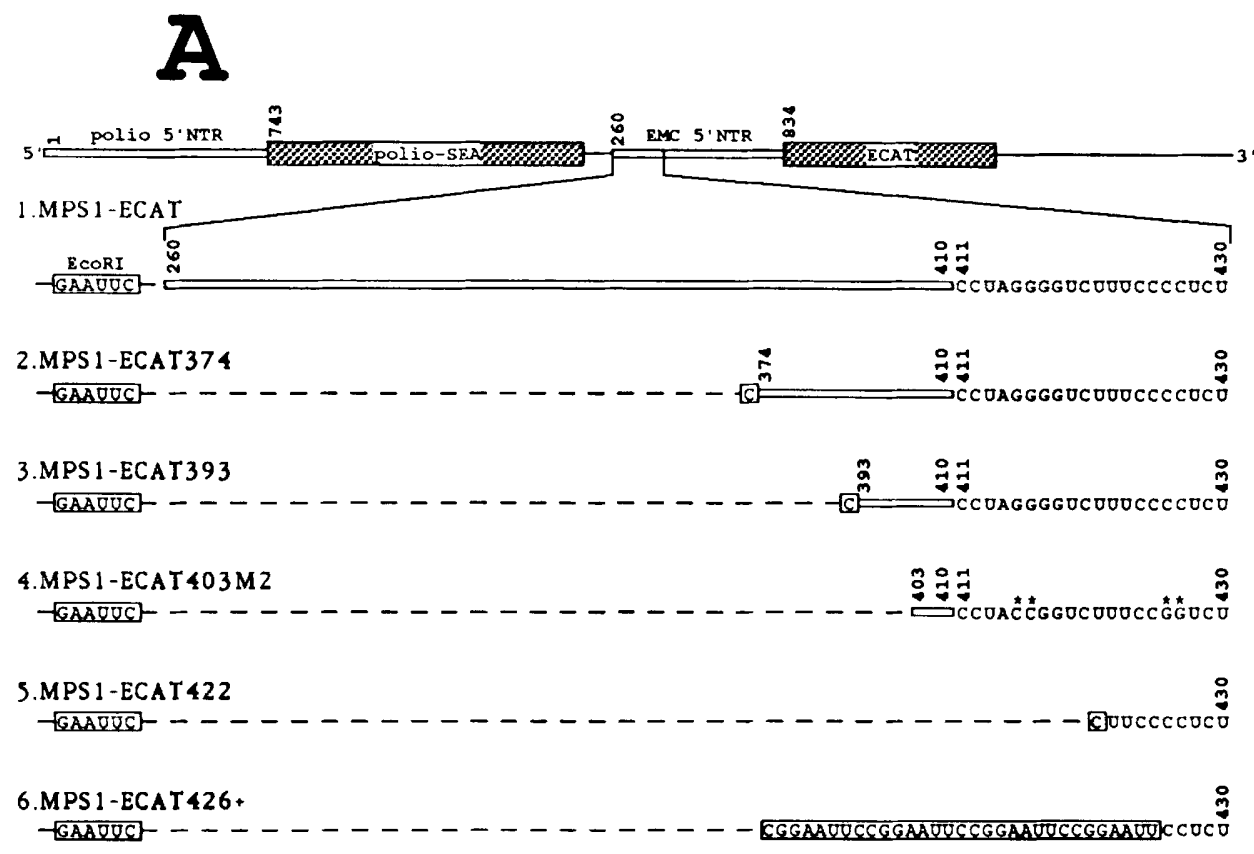

Figure 1. Determination of the 5 ' border of the EMCV IRES. (A) Schematic diagrams of mRNAs synthesized by in vitro transcription from plasmids deleted serially from the $5^{\prime}$ end of the EMCV $5^{\prime}$ NTR. The 5' NTRs of poliovirus and EMCV are shown as narrow boxes. The poliovirus polyprotein and viral sea hybrid-coding sequence are depicted as a stippled box indicated by polio-SEA. The EMCV polyprotein and CAT hybrid-coding sequence are depicted as a stippled box indicated by ECAT. The $3^{\prime}$-nontranslated region $13^{\prime}$ NTR) followed by the polio-SEA- and ECAT-coding sequences are depicted as lines. The linker sequences are shown in boxes. Some sequences in the $5^{\prime}$ NTR of EMCV are shown, and mutations in MPS1-ECAT403M2 are indicated by asterisks $\left(^{*}\right)$. The positions of nucleotides in the $5^{\prime}$ NTRs of poliovirus and EMCV are indicated by numbers written vertically. The sequences deleted in mRNAs are shown as broken lines. Figures are not drawn to scale. $(B)$ Analysis of ${ }^{35}$ S|methionine-labeled proteins synthesized in RRL by mRNAs shown in $A$. Lanes are labeled according to the mRNA species used in the in vitro translation reaction. The poliovirus-SEA and the EMCV-CAT hybrid proteins are indicated as SEA and CAT', respectively.

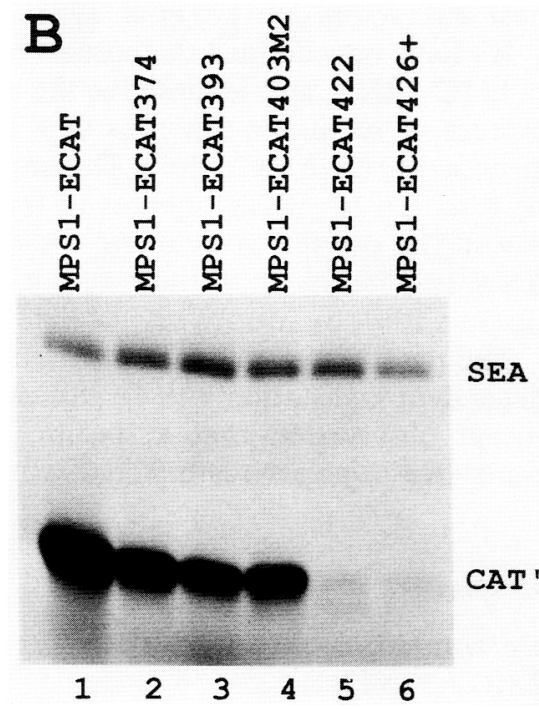

stream of nucleotide 479 dramatically reduced the translation efficiency of EMCV mRNA. We cannot explain at present why the method used by Shih et al. (1987) did not identify stem-loop E as an important element for translation.

\section{Determination of the $3^{\prime}$ border of the IRES in EMCV $5^{\prime}$ NTR}

Initiation of polyprotein synthesis of EMCV is thought to occur at the eleventh AUG of the 5' NTR (Palmenberg et al. 1984), an initiation codon with a favorable nucleotide context (AUAAUAUGG), according to Kozak (1986). Similarly favorable, however, is the tenth AUG (ACACGAUGA; see Fig. 6) which is just 8 nucleotides upstream of, and out of frame with, the eleventh AUG.
Furthermore, the initiating eleventh AUG codon is followed by another in-frame AUG (CAACCAUGA), just 3 codons downstream, which is also in a favorable nucleotide context. For 3' deletions of the EMCV 5' NTR, we decided to keep the AUAAUAUGG sequence intact and inserted into all constructs a suitable restriction site (XhoI) just upstream of this sequence. This maintained the context of the eleventh AUG.

Unfortunately, we failed to obtain a construct containing just an insertion of CCUCGAGG (Xhol linker) sequence by the serial deletion method described in the Materials and methods. Instead we obtained an mRNA with a deletion between nucleotides 811 and 827 showing reduced translational efficiency of the RNA (Fig. 2A, MPS1-ECAT811)-about fivefold compared to the wild-type RNA (Fig. 2B, cf. lane 7 with 8). Note that 


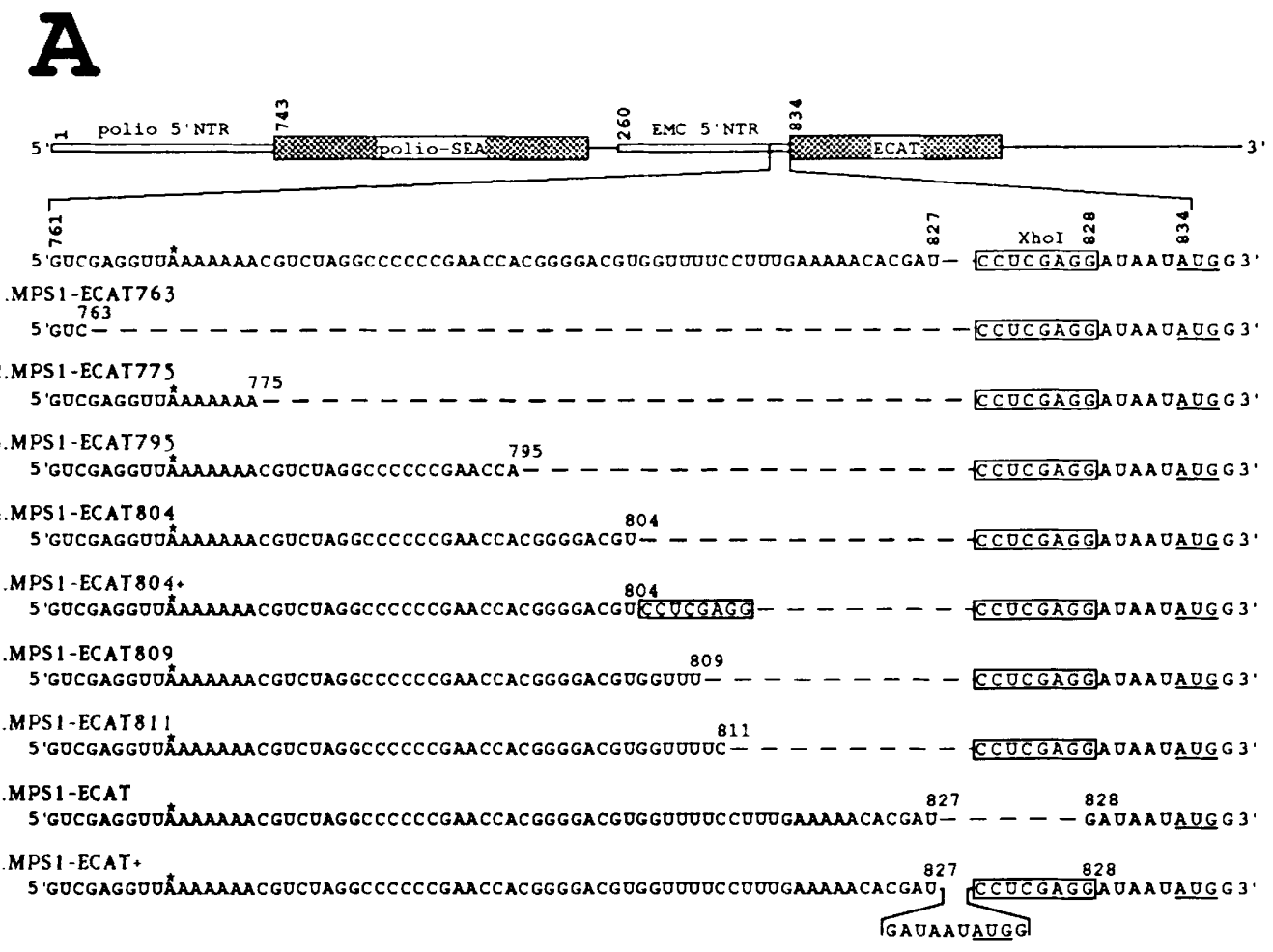

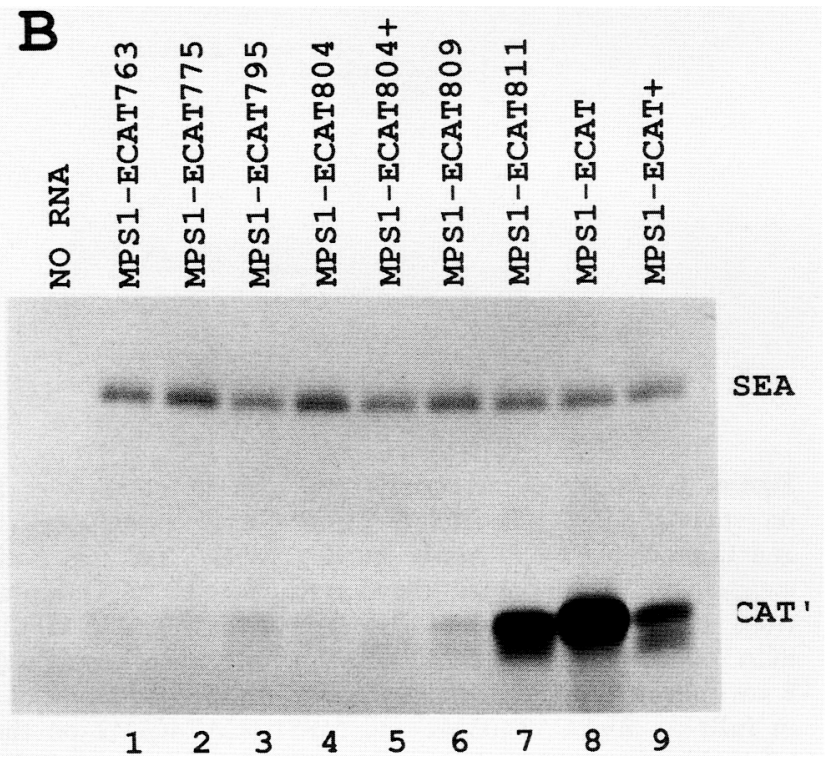

in this construct a pyrimidine-rich segment of 9 nucleotides (the same as in the wild-type sequence) has been reconstituted by the fusion of the sequence of the EMCV 5 ' NTR with that of the Xhol linker. However, the distance between the pyrimidine-rich segment and the eleventh AUG has been shortened. RNA transcripts deleted up to nucleotide 810 or further (Fig. 2A, constructs MPS1-ECAT763, MPS1-ECAT775, MPS1-ECAT804, and MPS1-ECAT809) showed a reduction in translation by a factor of 100 or more (Fig. 2B, cf. lanes 1-6 with lane 8). The replacement of a deleted sequence with a heterologous sequence CCUCGAGG failed to restore
Figure 2. Determination of the $3^{\prime}$ border of the EMCV IRES. (A) Schematic diagrams of mRNAs synthesized by in vitro transcription from plasmids deleted serially from the $3^{\prime}$ end of the EMCV $5^{\prime}$ NTR. Symbols and letters are as described in the legend to Fig. 1A. The addition of a nucleotide $\left[A\right.$; indicated by an asterisk $\left.\left(^{*}\right)\right]$ and the substitution of a nucleotide at nucleotide 831 (U to A) are in all of our constructions compared to the sequence published by Palmenberg et al. (1984). (B) Analysis of $\left[{ }^{35} \mathrm{~S}\right]$ methionine-labeled proteins synthesized in RRL by mRNAs shown in $A$. Lanes are labeled as described in the legend to Fig. 1B.

translational efficiency of the construct (see Fig. 2A, MPS1-ECAT804+; Fig. 2B, lane 5). The pyrimidine-rich sequence occurring in several picornaviral mRNAs, just upstream of the initiating AUG codon, has been noted previously by Beck et al. (1983). This region is shortened in transcripts of MPS1-ECAT809 that no longer support efficient translation. We suggest that the pyrimidinerich sequence with a critical length of 9 (or possibly 8) nucleotides plays an important role in the initiation of translation, possibly by determining which of the AUGs in this region is used for initiation.

Interestingly, the efficiency of translation of MPS1- 
ECAT795 and MPS1-ECAT809 mRNAs was about threefold higher than that of the other constructs containing deletions of the pyrimidine-rich sequence (Fig. 2B, cf. lanes 3 and 6 with lanes 1, 2, 4, and 5). A possible cause of this phenomenon will be discussed later. An insertion of an oligonucleotide (17 residues) with the sequence GAUAAUAUGGCCUCGAG duplicated the eleventh AUG (MPS1-ECAT +). The duplicated AUG, however, was out of frame with the ECAT cistron (Fig. 2A). The transcript containing this insertion produced 10 -fold less ECAT product $\left(\mathrm{CAT}^{\prime}\right)$. The reduction is probably due to the binding of ribosomes to the AUG of the insert, whereas CAT' is probably produced by translational reinitiation of ribosomes migrating 13 nucleotides upstream after finishing the preceding cistron (Peabody and Berg 1986).

Our data suggest that the $3^{\prime}$ border of EMCV IRES is the conserved pyrimidine-rich sequence. Furthermore, the distance between this pyrimidine-rich segment and the initiating AUG appears to influence translational efficiency. In some of the translations, however, we consistently see a band migrating slightly faster than CAT'. The AUG responsible for initiation of the faster migrating band is not known but may be the twelfth AUG. On the other hand, the tenth AUG appears not to be functioning in the intact IRES element.

A stem-loop structure near the 5' border of the IRES element is necessary for function

The deletion experiments at the $5^{\prime}$ border of the IRES (Fig. 1B) suggested that stem-loop E (see Fig. 6) was important for IRES function. This was tested by altering the sequence in the stem, as shown in Figure 3A. Specifically, we changed two $G$ residues to two $C$ residues (Fig. 3A), thereby destabilizing the stem near the loop, and determined the effect on translation either in a monocistronic mRNA (BS-ECAT403M1) or in a dicistronic mRNA (MPS1-ECAT403M1). As can be seen in Figure $3 \mathrm{~B}$, the mutation in one side of the stem lowered dramatically the synthesis of $\mathrm{CAT}^{\prime}$ directed by both the monocistronic BS-ECAT403M1 mRNA (lane 1) and the dicistronic MPS1-ECAT403M1 mRNA (lane 3).

Compensatory mutations restoring stem-loop structure E /GG to CC on one side, and CC to GG on the other side; Fig. 3A) restored translational efficiency of the monocistronic (BS-ECAT403M2) and dicistronic (MPS1-ECAT403M2) mRNAs to the level observed with wild-type sequence (Fig. 3B, lanes 2 and 4; also cf. lane 3 with 4 of Fig. 1B). Note that the higher yield of $\mathrm{CAT}^{\prime}$ with MPS1-ECAT (Fig. 3B, lane 5) is due to the presence of sequences upstream of nucleotide 403 that augment IRES function (see Fig. 1B, lanes 1, 3 and 4). We conclude that the secondary structure rather than the primary sequence in stem-loop $\mathrm{E}$ is important for the IRES function. Translational efficiencies of monocistronic mRNAs (BS-ECAT403M1 and BS-ECAT403M2) were slightly higher than those of corresponding dicistronic mRNAs containing the same mutations (MPS1ECAT403M1 and MPS1-ECAT403M2; Fig. 3B, cf. lanes

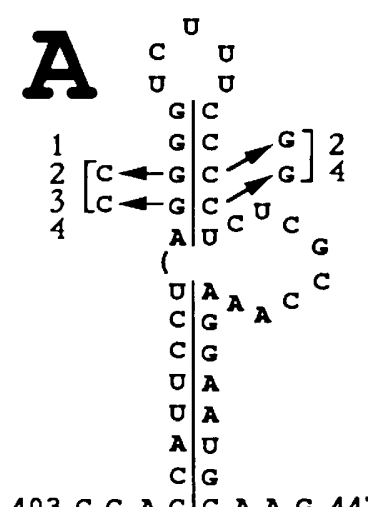

403 C G A GlC A A G 447

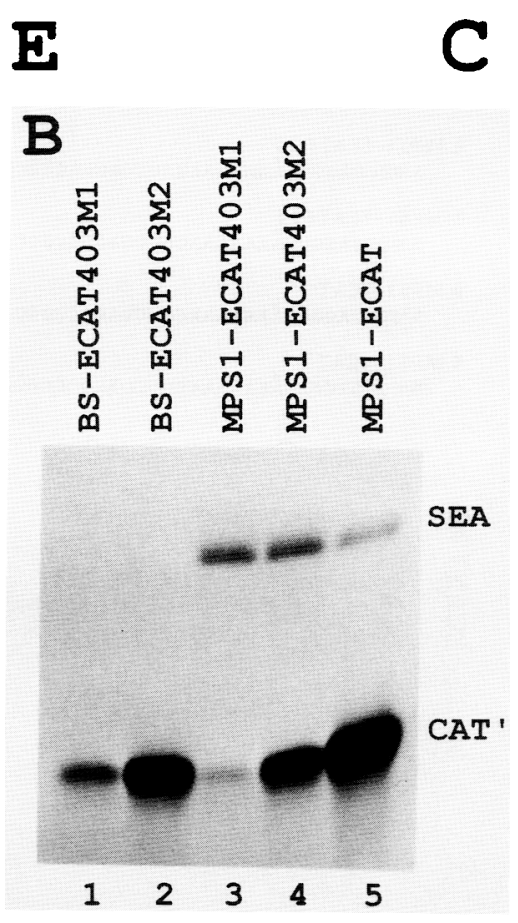

Figure 3. Effect of secondary structure of stem-loop E on translation. (A) Secondary structures of stem-loops $\mathrm{E}$ and C predicted by Pilipenko et al. (1989a). Note that both stem-loop C and E contain the loop sequence UCUUU. Mutations in mRNAs BS-ECAT403M1, BS-ECAT403M2, MPS1ECAT403M1 and MPS1-ECAT403M2 on one side of stem-loop $E$ are indicated as 1, 2, 3, and 4, respectively. Second mutations in mRNAs BS-ECAT403M2 and MPS1-ECAT403M2 on the other side of stem-loop E are indicated as 2 and 4, respectively. (B) Translational efficiencies of mRNAs containing mutations in stem-loop E. Translational products synthesized in RRL by monocistronic mRNAs (BS-ECAT403M1 and BS-ECAT403M2) and dicistronic mRNAs (MPS1-ECAT403M1 and MPS1ECAT403M2) were analyzed by SDS-PAGE. Lanes are labeled as described in the legend to Fig. $1 \mathrm{~B}$.

1 and 2 with 3 and $4 /$. We do not know the reason for the difference in translational efficiencies of mono- versus dicistronic-mRNAs. However, we consider it likely to be due to the difference in "accessibility" of factor(s) to the IRES, that is, a slower rate of attachment of factors/ 
ribosome to the IRES element buried in a dicistronic mRNA. Based on the data of Howell et al. (1990), scanning is not likely to contribute to the translational efficiency of these mRNAs.

\section{Binding of a cellular protein to stem-loop E}

We then explored the possibility that specific cellular proteins interact with the IRES element. Accordingly, we UV cross-linked proteins contained in RRL to ${ }^{32} \mathrm{P}$-labeled RNA probes. Because of the significance of stemloop $\mathrm{E}$ noted above, we concentrated on this genetic element (see Fig. 4A). As can be seen in Fig. 4B, several bands migrating as proteins of $36,43,50,57$, and $69 \mathrm{kD}$ were labeled by using this technique (lanes 1-4). All RNA probes employed yielded similar band patterns except that a band with an apparent molecular mass of 57 $\mathrm{kD}$ was seen only in experiments in which the probes contained an intact stem-loop E (Fig. 4B, lanes 1 and 4).
The material migrating at $57 \mathrm{kD}$ formed a doublet band. Longer digestion of a UV cross-linking reaction mixture with higher concentration of RNases showed the same pattern of protein bands (data not shown).

In experiments to identify the origin of the $57-\mathrm{kD}$ protein in RRL, we used a ribosomal salt wash (RSW) fraction of RRL as a source of protein in the binding studies instead of the entire lysate. As can be seen in Figure 4C (lane 1), a single $57-\mathrm{kD}$ protein bound strongly to stemloop $\mathrm{E}$, whereas the other proteins were hardly detectable. This observation suggests that a $57-\mathrm{kD}$ protein (referred to as p57) that interacts with the IRES may be a ribosome-associated molecule. One additional band migrating faster than p57 was detected on overexposure of the gel containing the UV-cross-linked proteins of the RSW. The significance of this observation is not yet known.

The binding of the RSW-derived p57 was analyzed further with RNA probes specific to the $5^{\prime}$ border of the
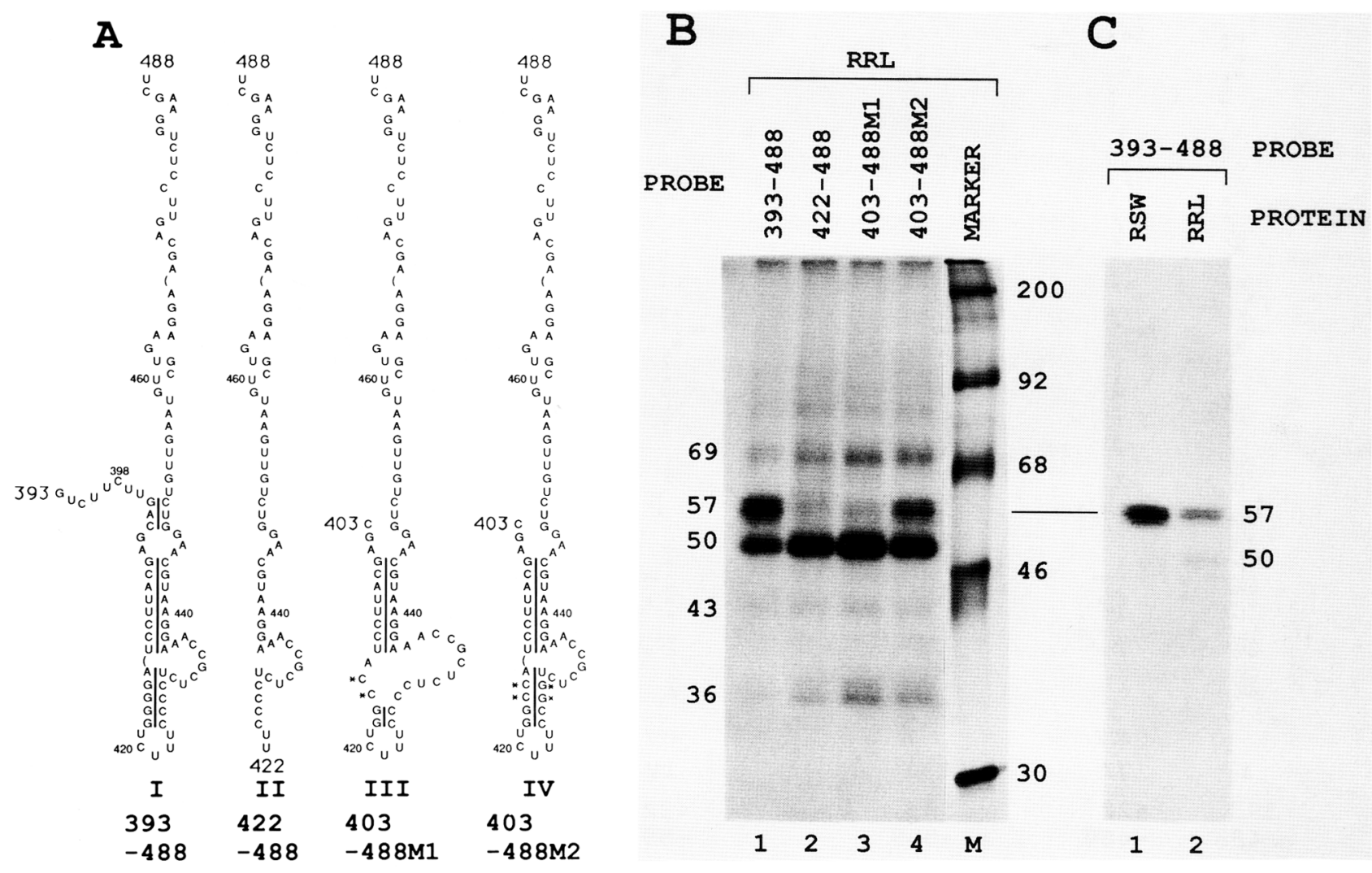

Figure 4. Identification of a cellular protein(s) binding to stem-loop E. (A) Presumed secondary structures of RNA probes used for UV cross-linking. Note that the nucleotide change from GG to CC destroys a part of the stem-loop E, as shown for the probe $403-488 \mathrm{Ml}$, and that the compensatory nucleotide change from CC to GG on the other side of stem-loop E restores the secondary structure, as shown for the probe $403-488 \mathrm{M} 2$. Positions of the nucleotides in the $5^{\prime}$ NTR of EMCV are indicated by numbers. (B) Analysis of UV cross-linked proteins from RRL elicited by ${ }^{32} \mathrm{P}$-labeled RNA probes shown in $A$. RRL proteins incubated with RNA probes were irradiated with UV light, digested with RNases, and analyzed by SDS-PAGE. Overexposure of an autoradiogram showed several bands with apparent molecular masses of $36,43,50,57$, and $69 \mathrm{kD}$. Note that appearance of the $57-\mathrm{kD}$ bands correlates well with translational efficiencies of mRNAs (see Fig. 1B, lanes 3-5, and Fig. 3B) containing the same stem-loop E as the probes used in the UV cross-linking reaction. Lanes are labeled according to the probes used in UV cross-linking reaction. (C) Comparison of protein species in RSW or in RRL shown by UV cross-linking reaction with the probe 393-488. The autoradiogrph was less exposed than the one in $B$. Note that one of the $57-\mathrm{kD}$ bands was enhanced in UV cross-linking reaction with a RSW fraction whereas other bands were reduced in the same reaction. Lanes are labeled according to protein sources used in the UV cross-linking reaction. 
EMCV IRES (Fig. 5A). Probe I, containing nucleotides $393-488$, bound p57 as well as probe III did (nucleotides 393-559), and no other protein bands originating from RSW were observed (Fig. 5B, lanes 1 and 5). Probe II (nucleotides 422-488) and probe IV (nucleotides 422-559) failed to bind $\mathrm{p} 57$ in contrast to those RNAs containing the entire stem-loop E (Fig. 5B, lanes 7 and 3). In the absence of RSW, no product was observed after UVcross-linking (Fig. 5B, lanes 2, 4, 6, and 8). No band was seen without UV-cross-linking (data not shown), an ob-

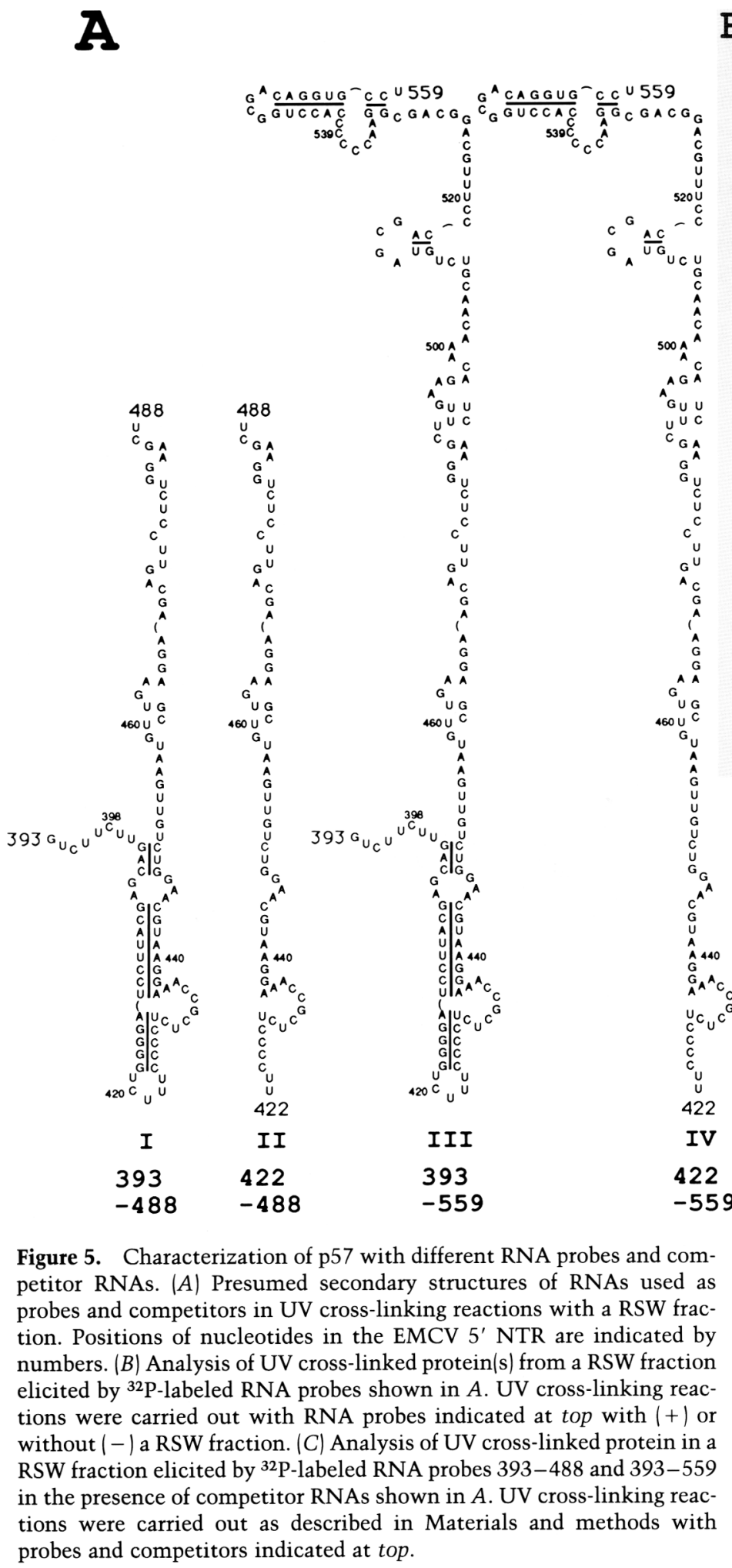

B

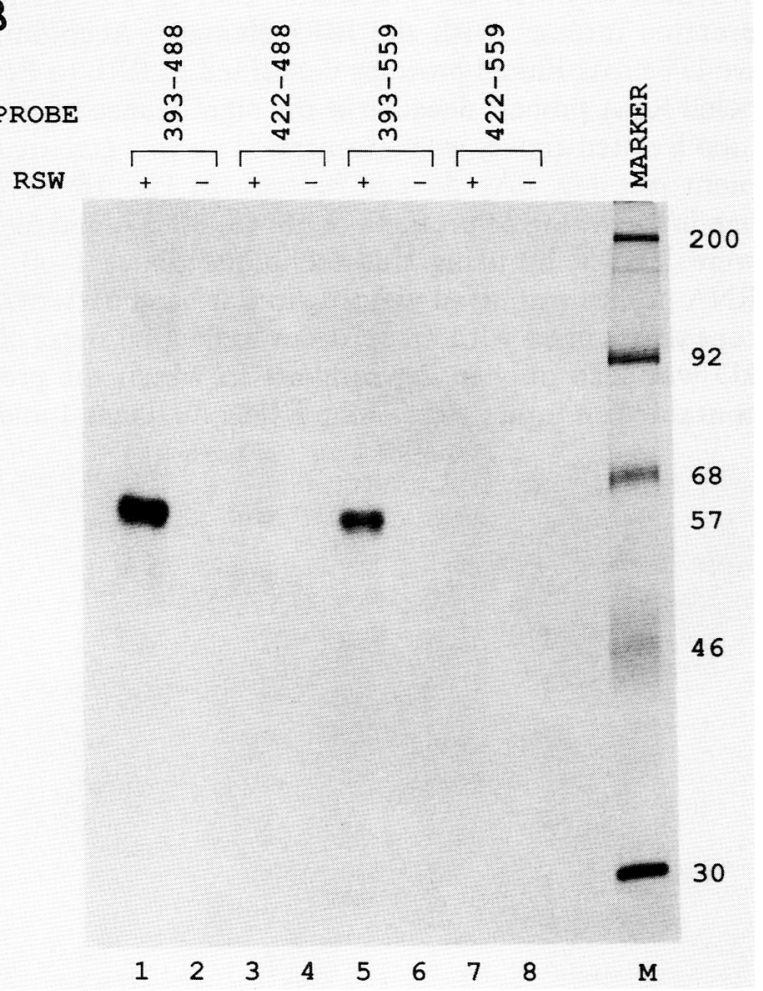

C

PROBE $\quad 393-488$

$393-559$
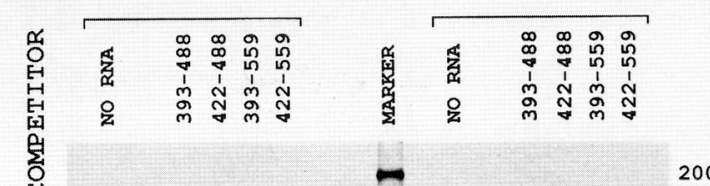

42

n

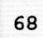

57 
servation suggesting that $\mathrm{p} 57$ is unlikely to form a transient covalent bond with the RNA. Transient covalent binding has been observed recently with RNA-recognizing proteins such as aminoacyl-tRNA synthetase (Starzyk et al. 1982) and bacteriophage R17 coat protein (Romaniuk and Uhlenbeck 1985).

Binding of $\mathrm{p} 57$ to RNA probe I was eliminated by competition with unlabeled RNAs containing the stem-loop E (probes I and III), but it was not influenced by competitor RNAs lacking the stem-loop structure (probes II and IV), as shown in Figure 5C (cf. lanes 2 and 4 with 3 and 5). The same result was obtained when binding to labeled probe III was subjected to competition with cold RNAs containing either intact stem-loop E or truncated sequences (Fig. 5C, cf. lanes 7 and 9 with 8 and $10)$.

In agreement with these data, the binding of p57 to probe I in Figure 4A (wild-type sequence) was greatly reduced in the presence of unlabeled competitor RNA of mutant probe IV (403-488M2 mutant RNA in which stem-loop E is restored; Fig. 4A), but not with RNA of probe III (403-488M1), the RNA with the destabilized stem-loop E (data not shown). Binding of the 36-, 43-, $50-$, and $69-\mathrm{kD}$ proteins seen in Figure $4 \mathrm{~B}$ was always reduced no matter which competitor RNA was used (data not shown). We conclude that p57 is a cellular protein that specifically binds to stem-loop E of the IRES of EMCV.

\section{Binding of cellular protein p57 to stem-loop E correlates with IRES function}

The ability of p57 to bind to stem-loop E correlated well with the translational efficiency of the synthetic mRNAs. RNA probes containing wild-type stem-loop E (structure I in Fig. 4A) or stem-loop E with four mutations that restore the stem adjacent to the loop (structure IV in Fig. 4A) strongly bound p57 (Fig. 4B, lanes 1 and 4). mRNAs containing these structures were efficient in translating $\mathrm{CAT}^{\prime}$ (see Fig. 1B, lanes 1-4; Fig. 3B, lanes 2 and 4). On the other hand, RNA probes containing either one-half of stem E (structure II in Fig. 4A) or a modified stem-loop $\mathrm{E}$ with destabilizing mutations (structure III in Fig. 4A) at best showed weak binding to p57 (Fig. 4B, lanes 2 and 3). Dicistronic mRNAs containing these deleted or modified structures in their EMCV IRES had greatly diminished translational efficiencies for $\mathrm{CAT}^{\prime}$ (Fig. 1B, lane 5; Fig. 3B, lane 3).

\section{Discussion}

We recently proposed that initiation of translation of EMCV RNA occurs by ribosomal internal entry into the $5^{\prime}$ NTR without the requirement for a free $5^{\prime}$ end (Jang et al. 1988, 1989). Such a mechanism is quite different from that proposed for capped cellular mRNAs (Kozak 1978), but the individual steps of ribosomal internal entry and the molecular elements required for such an event are not yet understood. We have begun to dissect the IRES of EMCV and have discovered a cellular protein that specifically interacts with a structural element of the IRES.

A stem-loop structure 400 nucleotides upstream from the initiation codon is crucial in translation of EMCV RNA

We reported previously that the full-length $5^{\prime}$ NTR of EMCV and a $5^{\prime}$ NTR beginning at nucleotide 260 (MPS1-ECAT) were equally efficient in protein synthesis (Jang et al. 1988), an observation suggesting that the nucleotides up to nucleotide 259 had no influence on translation. However, a deletion up to nucleotide 402 resulted in a fivefold reduction in translation when compared to MPS1-ECAT RNA, and a reduction was even seen when the deletion involved sequences only up to nucleotide 374 (Fig. 1B, cf. lane 1 with $2-4$ ). This observation suggests that a structural element, contributing to efficient translation, resides between nucleotides 260 and 402. On inspection of the proposed secondary structure of the EMCV 5' NTR (Pilipenko et al. 1989a), we observed that stem-loop C contains a UCUUU loop identical to that of stem-loop E (see Figs. 3 and 6). Because stem-loop $\mathrm{C}$ was removed in all $5^{\prime}$-deletion variants analyzed in this study, we consider it possible that, functionally, stem-loop $\mathrm{C}$ is a duplication of stem-loop $\mathrm{E}$ and may therefore augment translational efficiency. This hypothesis could be tested by replacing stem-loop E with stem-loop C.

A 5' deletion up to nucleotide 421 or base changes interrupting the stem reduced the translational efficiency drastically. This indicated the importance of stem-loop E, a structural element conserved among cardioviruses and aphthoviruses (Pilipenko et al. 1989a).

Binding of a cellular $57-k D$ protein may be an essential step in translation of EMCV RNA

The data presented in Figures $4 \mathrm{~B}$ and $5 \mathrm{~B}$ show that stem-loop $\mathrm{E}$ binds a cellular protein, p57. Binding is abolished when the stem adjacent to the UCUUU loop is destabilized by mutation but restored when mutations on both sides restore the secondary structure. Binding of p57 and translational efficiency covary, an observation suggesting strongly that the cellular polypeptide p57 plays a crucial role in translation of EMCV RNA. The properties of $\mathrm{p} 57$ are under investigation. The function of p57 in host cell metabolism is not yet known. It appears that $\mathrm{p} 57$ is a ribosome-bound protein, a property that would befit a role in mediating ribosome binding to the IRES. However, p57 exists in small quantities in the postribosomal fraction of RRL. A double band was seen to migrate at $\sim 57 \mathrm{kD}$ when proteins of RRL were $U V$ cross-linked to RNA probes (Fig. 4B), and it is therefore possible that p57 may exist in different forms (see also Fig. $4 \mathrm{Cl}$ that may differ, in turn, in their affinity for the ribosome.

Very recently, Borovjagin et al. (1990) have observed the binding of a protein from ascites carcinoma Krebs- 2 cells to nucleotides $315-485$ of the $5^{\prime}$ NTR of EMCV. 


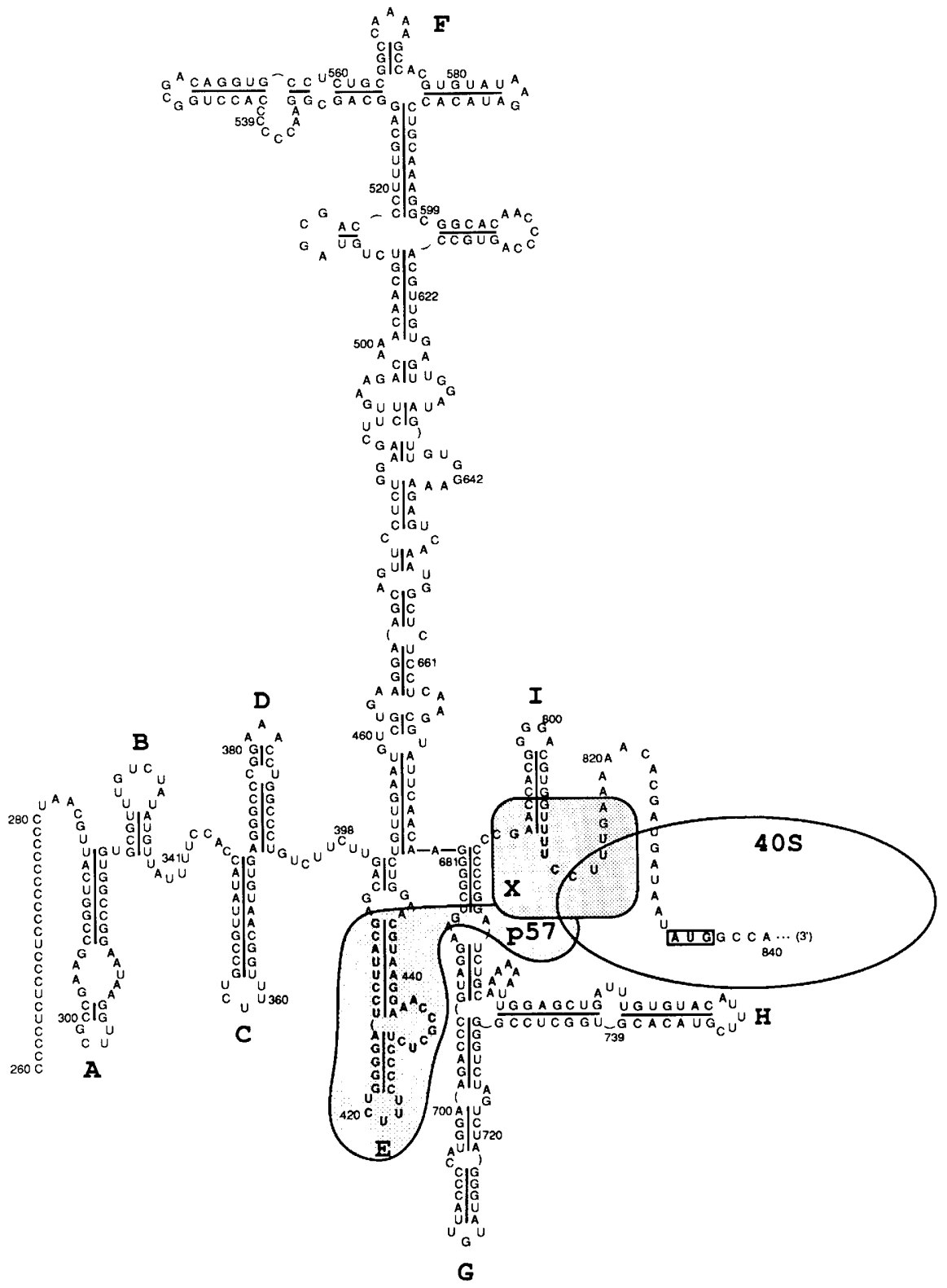

Figure 6. A model for translational initiation of EMCV mRNA by internal ribosomal entry. A protein that binds to stem-loop E (p57) and a putative protein that binds to the pyrimidine-rich sequence (X) are depicted as boxes shaded lightly and densely, respectively. A 40S ribosomal subunit is depicted as an oval. The secondary structure of the EMCV $5^{\prime}$ NTR [from the poly/C) stretch to the initiation codon of EMCV polyprotein shown in a boxl, predicted by Pilipenko et al. (1989a), is used in the illustration. The stem-loop structures are sequentially named by letters of the alphabet. Positions of nucleotides in the EMCV $5^{\prime}$ NTR are indicated by numbers.

This protein (p58) may be identical to p57 in its binding properties to the IRES element described here, although the investigators failed to discover $\mathrm{p} 57$ in RRL extracts. Furthermore, the role of Krebs-2 p58 in translation was not studied.

\section{A possible function of the pyrimidine-rich sequence} proximal to the initiating $A U G$ codon

Modification of the nucleotide sequence preceding the AUG initiating polyprotein synthesis of EMCV /the eleventh AUG, shown in a box in Fig. 6) strongly influences translation of ECAT. Replacement of 17 nucleotides (CUUUGAAAAACACGAUG) near the eleventh AUG with a linker sequence (CCUCGAGG) (see Fig. 2A, MPS1-ECAT811) reduced translational efficiency of the construct about fivefold (cf. Fig. 2B, lane 7 with 8). Translation was all but abolished when two more nucleotides were deleted (MPS1-ECAT809). Translation was not restored upon further deletion (MPS1-ECAT763, MPS1-ECAT775, MPS1-ECAT795, and MPS1ECAT804) (Fig. 2B, lanes 1-6). A pyrimidine-rich seg- 
ment with the sequence UUUUCCUUU therefore appears to be a critical region involved in the regulation of initiation of protein synthesis. Interestingly, in MPS1ECAT811 RNA, which directs efficient translation of ECAT gene (Fig. 2B, lane 7), the pyrimidine-rich segment is as long as the authentic EMCV 5' NTR $19 \mathrm{nu}-$ cleotides), although it differs in sequence by 2 nucleotides (UUUUCCCUC). This may suggest that the number of pyrimidines, and not necessarily the sequence, is essential for efficient IRES function. The position of the pyrimidine segment may also play a role in determining the translational initiation site. For example, the translational efficiency of MPS1-ECAT795 RNA, which contains a $\left(\mathrm{Cl}_{6}\right.$ stretch 20 nucleotides from the initiation codon, was clearly higher than that of other deletion constructs such as MPS1-ECAT804 (Fig. $2 \mathrm{~B}$, cf. lane 3 with 4|. Note that the distance of the C stretch to the initiation codon of MPS1-ECAT795 (19 nucleotides) is similar to that of the pyrimidine stretch to the initiation codon of MPS1-ECAT (18 nucleotides).

The UUUUCCCUC sequence in MPS1-ECAT811 is separated from the twelfth AUG codon at nucleotide 846 (834AUGGCCACAACCAUGA849) by 21 nucleotides. Presently, we do not know whether the ECAT product from MPS1-ECAT811 RNA is initiated at the eleventh or at the twelfth AUG (at nucleotide 846). A decision between these two possibilities can be made by amino-terminal sequencing of the translation product. On the other hand, the tenth AUG codon (at nucleotide 824 ) just upstream of the authentic initiation codon for polyprotein synthesis is rarely, if ever, recognized by the ribosome even though it contains a favorable Kozak's consensus sequence (824ACGAUGAUAAUAUGG837; see also Howell et al. 1990). These observations underscore the precision by which the IRES element directs the initiation of translation to a single AUG codon within the long 5' NTR. One would predict, however, that the tenth AUG can be used if the IRES element is $5^{\prime}$ deleted and, thus, its function is destroyed. This was indeed found by R. Jackson and his colleagues (Howell et al. 1990).

\section{How does the EMCV IRES work?}

The data presented here suggest that the EMCV IRES contains at least two domains important for function: stem-loop E and the pyrimidine-rich segment. These domains, which are conserved among cardioviruses and aphthoviruses (Beck et al. 1983; Pilipenko et al. 1989a), are separated by several hundred nucleotides, although they may be in close proximity in the tertiary structure.

A possible mechanism for the initiation of translation is illustrated schematically in Figure 6. Polypeptide p57, a cellular RNA-binding protein, will specifically attach to stem-loop E of the IRES. By means of its apparent affinity to the ribosome, it will bring the $40 \mathrm{~S}$ ribosomal subunit into the vicinity of potential initiation codons. Whether the 40S subunit selects the eleventh AUG codon by hybridization of a purine-rich sequence near the $3^{\prime}$ end of its $18 \mathrm{~S}$ RNA to the pyrimidine-rich segment of the IRES or whether a polypeptide (denoted as X in Fig. 6) that recognizes the pyrimidine-rich sequence is involved remains to be investigated. The structures between stem-loop $E$ and the pyrimidine-rich segment in the EMCV 5' NTR may also be essential for IRES function (G.W. Witherell, S.K. Jang, and E. Wimmer, unpubl.). Kühn et al. (1990) found that modifications in the corresponding region of the FMDV $5^{\prime}$ NTR strongly reduced translational efficiency. These investigators also recognized the importance of the pyrimidine-rich segment for IRES function of FMDV mRNA.

Many features of the EMCV IRES, which is representative of cardioviruses and aphthovinuses, appear to be quite different from features of the poliovirus IRES, which is representative of enteroviruses and rhinoviruses (see introductory section). (1) Although the borders of the poliovirus IRES have not yet been defined, it is known that an essential element (a stem-loop structure consisting of nucleotides 567-627; Pilipenko et al. $1989 \mathrm{~b}$ ) of the polio IRES is separated from the initiating AUG codon by $\sim 100$ nucleotides (BienkowskaSzewczyk and Ehrenfeld 1988). These 100 nucleotides can be deleted without loss of viral viability (Kuge and Nomoto 1987). Insertion of AUG codons into these 100 nucleotides disturbs viral replication, an observation suggesting that the ribosomal subunit may scan through this region after it has attached to the IRES (Kuge et al. 1989). Interestingly, these 100 nucleotides have been naturally deleted in rhinovirus RNA (Callahan et al. 1985; Skern et al. 1985). (2) As mentioned before, Meerovitch et al. (1989) identified a cellular protein (p52) that specifically binds to the stem-loop structure (nucleotides 567-627). Del Angel et al. (1989) have also found that cellular proteins form a complex with the poliovirus $5^{\prime}$ NTR, and they have proposed that an eukaryotic initiation factor (eIF-2 $\alpha$ ) is in the complex. On the basis of the difference in primary and secondary structure of the protein-binding stem-loops of EMCV and poliovirus IRES elements, and because probe I (Fig. 4A) does not compete with poliovirus RNA for the binding to $\mathrm{p} 52$ (N. Sonenberg and S.K. Jang, unpubl.|, we determined that the p52 described by Meerovitch et al. (1989) and the p57 described here are different molecules.

The differences seen in picornavirus IRES elements must not distract from their common function: initiation of protein synthesis in a cap-independent fashion (Jang et al. 1988, 1989; Pelletier and Sonenberg 1988, 1989). Such differences are likely to play a role in determining host range or tissue tropism: The elements may require different sets of factors to function efficiently in different cells. The difference between the translational efficiency of EMCV RNA and poliovirus RNA in RRL may be taken as a simple but telling example. Whereas EMCV RNA is a superb mRNA in RRL, poliovirus RNA hardly stimulates protein synthesis in this system, and much of the protein produced in RRL under the direction of poliovirus RNA is initiated at the wrong AUGs (Dorner et al. 1982, 1984; Nicklin et al. 1987). Addition of HeLa cell factors to RRL, on the other hand, dramatically stimulates translation of poliovirus RNA in RRL, and the viral polyprotein is initiated at the proper AUG 
at the end of the $5^{\prime}$ NTR (Brown and Ehrenfeld 1979; Dorner et al. 1984; Svitkin et al. 1985, 1989).

\section{Are IRES-like elements functioning in cellular protein synthesis?}

The IRES elements of EMCV and poliovirus can function in mammalian cell extracts or in intact cells without the involvement of viral gene products (Jang et al. 1988, 1989; Pelletier and Sonenberg 1988, 1989). This indicates the presence in mammalian cells of factors that recognize and utilize these structures in the $5^{\prime}$ NTRs of picornaviral mRNAs. It follows that cellular factors, such as p57, are also likely to interact with IRES-like structures in cellular mRNAs, thereby, in specific cases, overriding cap-dependent initiation of translation. So far, no cellular IRES has been described, but the $5^{\prime}$ NTR of glucose-regulated protein 78/immunoglobulin heavy chain-binding protein (GRP78/BiP) is a candidate to harbor such an element. This is based on the observation that the translation of GRP78/BiP is enhanced in poliovirus-infected cells and therefore may direct cap-independent initiation of translation (Sarnow 1989). Indeed, the 5' NTR of GRP78/BiP mRNA, when engineered into the center of a dicistronic mRNA, can efficiently promote translation of the second cistron in vivo (P. Sarnow, pers. comm.). We consider it likely that many more cellular mRNAs with $5^{\prime}$ NTRs similar to that of GRP78/BiP will be discovered in the future.

\section{Materials and methods}

\section{Construction of plasmids}

Enzymes for cloning and modifying DNA were purchased from New England Biolabs, Inc., and Bethesda Research Laboratories, Inc. DNA manipulations were done by standard procedures, or as indicated (Maniatis et al. 1982). Plasmid pMPS1-ECAT containing a T7 promoter and a dicistronic coding sequence was derived from plasmids pMPS1-E2A (Jang et al. 1988) and pBSECAT (Jang et al. 1989) by replacing the EMCV-2A sequence of pMPS1-E2A with the EMCV-CAT sequence of pBS-ECAT. Upon in vitro transcription with T7 polymerase, pMPS1-ECAT produces a dicistronic mRNA containing, in $5^{\prime}$ to $3^{\prime}$ order, the first cistron consisting of the poliovirus $5^{\prime}$ NTR and the coding region of the viral sea oncogene, followed by the second cistron consisting of the EMCV 5' NTR and the coding region of the CAT gene. In this construct, the CAT gene product carries an extra 17 amino acids originating from the amino-terminal portion of the EMCV polyprotein.

To make plasmids containing serial deletions from the $5^{\prime}$ end of the EMCV 5' NTR (pMPS1-ECAT374, pMPS1-ECAT393, pMPS1-ECAT422, and pMPS1-ECAT426+l, plasmid pMPS1ECAT was digested with EcoRI, and the smallest fragment containing the 5' NTR of EMCV (nucleotides 260-833) and a part of the CAT-coding sequence was isolated following low melting point (LMP) agarose gel electrophoresis. The isolated fragment $(1 \mu \mathrm{g})$ was incubated with 0.5 unit of exonuclease III, which has $3^{\prime}$-exonuclease activity, for 5, 10, 15, 20, and $40 \mathrm{~min}$. After combining all of the reaction mixtures, the singlestranded ends of the fragments produced by the exonuclease III were removed by $\mathrm{S} 1$ nuclease, and residual single-stranded portions of the DNAs were filled in by Klenow fragment of Esche- richia coli DNA polymerase. An EcoRI linker (5'GGAATTCC-3') was ligated to both ends of the blunt-ended DNA fragment, followed by double restriction enzyme digestion with EcoRI and HindIII and isolation of the smaller fragments. These fragments, which had various deletions at the end of the EcoRI linker side and fixed ends at the HindIII side, were ligated with two other fragments of pMPS1-ECAT: the smaller fragment of pMPS1-ECAT /generated by $P_{V u I}$ and HindIII digestion), and the larger fragment of pMPS1-ECAT (generated by EcoRI and $P v u I$ digestion). The ligated DNAs were transformed into $E$. coli cells and screened by use of restriction enzymes. Deleted portions of plasmids were identified by a dideoxynucleotide-sequencing method with a primer hybridizing to nucleotides 505-519 of the EMCV 5' NTR.

Plasmids used for transcription of dicistronic mRNAs containing serial deletions from the $3^{\prime}$ end of the EMCV 5' NTR (pMPS1-ECAT763, pMPS1-ECAT775, pMPS1-ECAT795, pMPS1-ECAT804, pMPS1-ECAT804 +, pMPS1-ECAT809, pMPS1-ECAT811, and pMPS1-ECAT + ) were constructed as follows. Plasmid pBS-ECAT(XhoI) containing a XhoI site and the initiation codon of the EMCV polyprotein at the Ball site in the plasmid pBS-ECAT was constructed by blunt-end ligation of a linker (5'-CCATTATATCCTCGAGGATAATATGG-3') and the plasmid pBS-ECAT partially digested with Ball enzyme. Plasmid pMPS1-ECAT(Xhol) containing a Xhol site was constructed by a blunt-end ligation of a XhoI linker (5'CCTCGAGG-3'), and plasmid pMPS1-ECAT linearized with BstXI and treated with T4 DNA polymerase. Plasmid pMPS1ECAT10 was constructed by a ligation of the smaller fragment of pBS-ECAT(XhoI) (generated by $\mathrm{HpaI}$ and $\mathrm{XhoI}$ digestion) and the larger fragment of pMPSI-ECAT(XhoI) (generated by HpaI and $X h o I$ digestion). The final plasmids containing serial deletions at the $3^{\prime}$ part of the EMCV 5' NTR were constructed by ligation of the larger fragment of pMPS1-ECAT10 /generated by $X$ hoI and HindIII digestion) and serially deleted fragments of pS32AIII (Jang et al. 1988). The serial deletion of pS32AIII was performed as described above except that Ball restriction was used instead of EcoRI and incubation times for exnuclease III treatment were $3,6,9,12$, and $15 \mathrm{~min}$. The serially deleted pS32AIII fragments were ligated with a XhoI linker $15^{\prime}$ CCTCGAGG-3') and then digested with XhoI and HindIII. The smaller fragment of the digested DNA was ligated with the larger fragment of pMPS1-ECAT10 described above. The resulting plasmids were screened by restriction enzymes and sequenced by use of a CAT primer $\left(5^{\prime}\right.$-GGATATATCAACGGTGG-3') hybridizing to a CAT-coding sequence.

Plasmid pBS-ECAT403Ml was constructed by a three-fragment ligation of the larger fragment of pBS-M + (Stratagene; generated by EcoRI and PstI digestion), the 2530-nucleotide fragment of pBS-ECAT /generated by HindIII and PstI digestion), and the 90-nucleotide fragment produced by a polymerase chain reaction (PCR; from the EcoRI to the HindIII site). The PCR was carried out as recommended by the supplier (PerkinElmer Cetus) with primers (5'-GGGAATTCGAGCATTCCTACCGGTCTTTCCCCTCTC-3' and the CAT primer described above) and plasmid pBS-ECAT as template. Plasmid pBS-ECAT403M2 was constructed similarly to pBSECAT403Ml, but a different primer (5'-GGGAATTCGAGCATTCCTACCGGTCTTTCCGGTCTCGCCAAA-3') was used for the EMCV sequence. Plasmid pMPS1-ECAT403M1 was constructed by three-fragment ligation of the 5287-nucleotide fragment of pMPS1-ECAT /generated by EcoRI and PvuI digestion), the 3356-nucleotide fragment of pMPS1-ECAT (generated by HindIII and PvuI digestion), and the 90 -nucleotide PCR fragment used for pBS-ECAT403M1 construction. Plasmid pMPS1-ECAT403M2 was constructed similarly to pMPS1- 
ECAT403M2, but the PCR fragment for pBS-ECAT403M2 was used instead of the PCR fragment for pBS-ECAT403M1. The fidelity of all portions of plasmids generated by PCR was confirmed by sequencing.

Plasmid pBS-ECAT393 was constructed by three-fragment ligation of the 3165-nucleotide fragment of pBS-ECAT /generated by EcoRI and PstI digestion), the 2324-nucleotide fragment of pBS-ECAT (generated by KpnI and PstI digestion), and the 309nucleotide fragment of pMPS1-ECAT393 /generated by EcoRI and KpnI digestion). Plasmid pBS-ECAT422 was constructed similarly to pBS-ECAT393, but the 279-nucleotide fragment of pMPS1-ECAT422 (generated by EcoRI and KpnI digestion) was used instead of the 309-nucleotide fragment of pMPS1ECAT393.

\section{In vitro transcription and translation}

The plasmids purified by $\mathrm{CsCl}$ gradient centrifugation were linearized with different restriction enzymes prior to in vitro transcription. All plasmids whose transcripts were used for in vitro translation were digested with $H p a I$, an enzyme that cleaves plasmids after the CAT-coding sequence. To generate the probes $393-488,422-488,403-488 \mathrm{M} 1,404-488 \mathrm{M} 2$, 393-559, and 422-559, we used pBS-ECAT393 digested with HindIII, pBS-ECAT422 digested with HindIII, pBS-ECAT403MI digested with HindIII, pBS-ECAT403M2 digested with HindIII, pBS-ECAT393 digested with BgII, and pBS-ECAT422 digested with $B g l I$, repectively. T7 RNA polymerase was a kind gift of John J. Dunn. Transcription reactions were carried out as described previously (van der Werf et al. 1986). Transcription of ${ }^{32} \mathrm{P}$-labeled RNA was carried out similarly to that of unlabeled RNA, but $10 \mu \mathrm{M}$ of unlabeled UTP and ${ }^{32}$ P-labeled UTP (120 $\mu \mathrm{Ci}$ ) were used instead of $1 \mathrm{mM}$ of unlabeled UTP.

In vitro translation of the RNA transcripts was performed in $\mathrm{RRL}$, as described by the supplier (Promega). The final RNA concentration in the reaction mixtures was $30 \mathrm{~nm}$, which is favorable for EMCV mRNA translation (Jang et al. 1988). Translation was carried out at $30^{\circ} \mathrm{C}$ for $60 \mathrm{~min}$; protein synthesis was measured by incorporation of ${ }^{35} S \mid$ methionine. Translation products were analyzed on $12.5 \%$ SDS-polyacrylamide gels by use of the buffer system described by Nicklin et al. (1987). Gels were treated with $\mathrm{En}^{3} \mathrm{Hance}$ (New England Nuclear Corp.|, dried, and exposed to Kodak XAR-5 film for $18 \mathrm{hr}$. Translation products were quantified using an Ambis Radioanalytic Imaging System (Ambis System, Inc.).

\section{UV cross-linking of RNAs}

The UV cross-linking reaction was performed as described by Meerovitch ct al. (1989), with several modifications. Gel-purified RNA probes ( $10^{4}$ to $\left.10^{5} \mathrm{cpm}\right)$, labeled with [32P]UTP, were incubated at $30^{\circ} \mathrm{C}$ for $20 \mathrm{~min}$ in a $30-\mu \mathrm{l}$ total volume of binding buffer (Konarska and Sharp 1986) into which $\sim 75 \mu \mathrm{g}$ of RRL or RSW proteins were added. For competition assays, $\sim 2.8 \mu \mathrm{g}$ of unlabeled RNAs were added in binding buffer and incubated at $30^{\circ} \mathrm{C}$ for $10 \mathrm{~min}$ prior to adding labeled RNAs. Samples were irradiated with UV light on ice for $30 \mathrm{~min}$ with a UV-Stratalinker (Stratagene). Unbound RNAs were digested with $20 \mu \mathrm{g}$ of RNase $A$ and 20 units of RNase Tl by incubating at $37^{\circ} \mathrm{C}$ for 30 min. Samples were analyzed by SDS-PAGE electrophoresis followed by autoradiography. Preparation of RSW from RRLs was by the method of Schreier and Staehelin (1973).

\section{Acknowledgments}

We thank Frank Ma for technical help, Christopher U. T. Hellen for critical reading of the manuscript, and Peter Sarnow for very useful suggestions and discussions. We are grateful to
Nahum Sonenberg for providing an RNA transcript corresponding to nucleotides 559-624 of poliovirus type 2 (Lansing) and John J. Dunn for T7 RNA polymerase. This research was supported, in part, by U.S. Public Health Service grants AI-15122 and CA-28146 from the National Institutes of Health. The publication costs of this article were defrayed in part by payment of page charges. This article must therefore be hereby marked "advertisement" in accordance with 18 USC section 1734 solely to indicate this fact.

\section{References}

Beck, E., S. Forss, K. Strebel, R. Cattaneo, and G. Feil. 1983. Structure of the FMDV translation initiation site and of the structural proteins. Nucleic Acids Res. 11: 7873-7885.

Bienkowska-Szewczyk, K. and E. Ehrenfeld. 1988. An internal 5 -noncoding region required for translation of poliovirus RNA in vitro. $/$. Virol. 62: 3068-3072.

Borovjagin, A.V., A.G. Evstafieva, T. Yu. Ugarova, and I.N. Shatsky. 1990. A factor that specifically binds to the 5 '-untranslated region of encephalomyocarditis virus RNA. FEBS Lett. 261: 237-240.

Brown, F. 1979. Structure-function relationships in the picornaviruses. In The molecular biology of picornaviruses (ed. R. Pérez-Bercoff), pp. 49-72. Plenum Press, New York/ London.

Brown, B.A. and E. Ehrenfeld. 1979. Translation of poliovirus RNA in vitro: Changes in cleavage pattern and initiation sites by ribosome salt wash. Virology 97: 396-405.

Callahan, P.L., S. Mizutani, and R.J. Colonno. 1985. Molecular cloning and complete sequence determination of RNA genome of human rhinovirus type 14. Proc. Natl. Acad. Sci. 82: 732-736.

Del Angel, R.M., A.G. Papavassiliou, C. Fernández-Tomás, S.J. Silverstein, and V.R. Racaniello. 1989. Cell proteins bind to multiple sites within the $5^{\prime}$ untranslated region of poliovirus RNA. Proc. Natl. Acad. Sci. 86: 8299-8303.

Dorner, A.J., L.F. Dorner, G.R. Larsen, E. Wimmer, and C.W. Anderson. 1982. Identification of the initiation site of poliovirus polyprotein synthesis. I. Virol. 42: 1017-1028.

Dorner, A.J., B.L. Semler, R.J. Jackson, R. Hanecak, E. Duprey, and E. Wimmer. 1984. In vitro translation of poliovirus RNA: Utilization of internal initiation sites in reticulocyte lysate. I. Virol. 50: 507-514.

Hewlett, M.J., J.K. Rose, and D. Baltimore. 1976. 5'-Terminal structure of poliovinus is pUp. Proc. Natl. Acad. Sci. 73: 327-330.

Holland, J.J., K. Spindler, F. Horodyski, E. Grabau, S. Nichol, and S. VandePol. 1982. Rapid evolution of RNA genomes. Science 215: 1577-1585.

Howell, M.T., A. Kaminski, and R.J. Jackson. 1990. Unique features of initiation of picornavirus RNA translation. In New aspects of positive-strand RNA viruses (ed. M.A. Brinton), pp. 144-151. American Society for Microbiology, Washington, D.C.

Jang, S.K., M.V. Davies, R.J. Kaufman, and E. Wimmer. 1989. Initiation of protein synthesis by internal entry of ribosomes into the $5^{\prime}$ nontranslated region of encephalomyocarditis virus RNA in vivo. J. Virol. 63: 1651-1660.

Jang, S.K., H.-G. Kräusslich, M.J.H. Nicklin, G.M. Duke, A.C. Palmenberg, and E. Wimmer. 1988. A segment of the 5' nontranslated region of encephalomyocarditis virus RNA directs internal entry of ribosomes during in vitro translation. I. Virol. 62: 2636-2643.

Konarska, M.M. and P.A. Sharp. 1986. Electrophoretic separation of complexes involved in the splicing of precursors to mRNAs. Cell 46: 845-855. 
Kozak, M. 1978. How do eukaryotic ribosomes select initiation regions in messenger RNA? Cell 15: 1109-1123.

- 1986. Point mutations define a sequence flanking the AUG initiator codon that modulate translation by eukaryotic ribosomes. Cell 44: 283-292.

Kuge, S. and A. Nomoto. 1987. Construction of viable deletion and insertion mutants of the Sabin strain type 1 poliovirus: Function of the $5^{\prime}$ noncoding sequence in viral replication. $J$. Virol. 61: 1478-1487.

Kuge, S., N. Kawamura, and A. Nomoto. 1989. Genetic variation occurring on the genome of an in vitro insertion mutant of poliovirus type 1. J. Virol. 63: 1069-1075.

Kühn, R., N. Luz, and E. Beck. 1990. Functional analysis of the internal translation initiation site of foot-and-mouth disease virus. J. Virol. (in press).

Lee, Y.F., A. Nomoto, and E. Wimmer. 1976. The genome of poliovirus is an exceptional eukaryotic mRNA. Prog. Nucleic Acid Res. Mol. Biol. 19: 89-96.

Maniatis, T., E.F. Fritsch, and J. Sambrook. 1982. Molecular cloning: A laboratory manual. Cold Spring Harbor Laboratory, Cold Spring Harbor, New York.

Meerovitch, K., J. Pelletier, and N. Sonenberg. 1989. A cellular protein that binds to the 5 '-noncoding region of poliovirus RNA: Implications for internal translation initiation. Genes Dev. 3: 1026-1034.

Nicklin, M.J.H., H.-G. Kräusslich, H. Toyoda, J.J. Dunn, and E. Wimmer. 1987. Poliovirus polypeptide precursors: Expression in vitro and processing by exogenous $3 \mathrm{C}$ and $2 \mathrm{~A}$ proteinases. Proc. Natl. Acad. Sci. 84: 4002-4006.

Nomoto, A., Y.F. Lee, and E. Wimmer. 1976. The $5^{\prime}$ end of poliovirus mRNA is not capped with $\mathrm{m}^{7} \mathrm{G}\left(5^{\prime}\right) \mathrm{pppNp}$. Proc. Natl. Acad. Sci. 73: 375-380.

Nomoto, A., N. Kitamura, F. Golini, and E. Wimmer. 1977. The 5'-terminal structures of poliovirion RNA and poliovirus mRNA differ only in the genomic-linked protein VPg. Proc. Natl. Acad. Sci. 74: 5345-5349.

Palmenberg, A.C. 1987. Comparative organization and genome structure in picornaviruses. In Positive strand RNA viruses (ed. M.A. Brinton and R.R. Rueckert), pp. 25-34, vol. 54. UCLA Symposia Cellular Biology. Alan R. Liss, New York.

Palmenberg, A.C., E.M. Kirby, M.R. Janda, N.L. Drake, G.M. Duke, K.F. Potratz, and M.S. Collett. 1984. The nucleotide and deduced amino acid sequences of the encephalomyocarditis viral polyprotein coding region. Nucleic Acids Res. 12: $2969-2985$.

Peabody, D.S. and P. Berg. 1986. Termination-reinitiation occurs in the translation of mammalian cell mRNA. Mol. Cell. Biol. 6: 2695-2703.

Pelletier, J. and N. Sonenberg. 1988. Internal binding of ribosomes to the $5^{\prime}$ noncoding region of a eukaryotic mRNA: Translation of poliovirus. Nature 334: $320-325$.

. 1989. Internal binding of eucaryotic ribosomes on poliovirus RNA: Translation in HeLa cell extracts. J. Virol. 63: $441-444$

Pettersson, R.F., J.B. Flanegan, J.K. Rose, and D. Baltimore. 1977. 5'-Terminal nucleotide sequence of poliovirus polyribosomal RNA and virion RNA are identical. Nature 268: $270-272$.

Pilipenko, E.V., V.M. Blinov, B.K. Chernov, T.M. Dmitrieva, and V.I. Agol. 1989a. Conservation of the secondary structure elements of the $5^{\prime}$-untranslated region of cardio- and aphothovirus RNAs. Nucleic Acids Res. 17: 5701-5711.

Pilipenko, E.V., V.M. Blinov, L.I. Romanova, A.N. Sinyakov, S.V. Maslova, and V.I. Agol. 1989b. Conserved structural domains in the 5 '-untranslated region of picornaviral genomes: An analysis of the segment controlling translation and neur- ovirulence. Virology 168: 201-209.

Porter, A., N.H. Carey, and P. Fellner. 1974. Presence of a large poly $(\mathrm{rC})$ tract within the RNA of encephalomyocarditis virus. Nature 248: 675-678.

Reanney, D.C. 1984. The molecular evolution of RNA viruses. Symp. Soc. Gen. Microbiol. 35: 175-196.

Rivera, V.M., J.D. Welsh, and J.V. Maizel, Jr. 1988. Comparative sequence analysis of the $5^{\prime}$ noncoding region of enteroviruses and rhinoviruses. Virology 165: 42-50.

Romaniuk, P.J. and O.C. Uhlenbeck. 1985. Nucleoside and nucleotide inactivation of R17 coat protein: Evidence for a transient covalent RNA-protein bond. Biochemistry 24: 4239-4244.

Sangar, D.V., D.N. Black, D.J. Rowlands, T.J.R. Harris, and F. Brown. 1980. Location of the initiation site for protein synthesis of foot-and-mouth disease virus RNA by in vitro translation of defined fragments of the RNA. I. Virol. 33: $59-68$.

Sarnow, P. 1989. Translation of glucose-regulated protein $78 /$ immunoglobulin heavy-chain binding protein mRNA is increased in poliovirus-infected cells at a time when cap-dependent translation of cellular mRNAs is inhibited. Proc. Natl. Acad. Sci. 86: 5795-5799.

Schreier, M.H. and T. Staehelin. 1973. Initiation of mammalian protein synthesis: the importance of ribosome and initiation factor quality for the efficiency of in vitro systems. J. Mol. Biol. 73: 329-349.

Shih, D.S., I.-W. Park, C.L. Evans, J.M. Jaynes, and A.C. Palmenberg. 1987. Effects of cDNA hybridization on translation of encephalomyocarditis virus RNA. I. Virol. 61: 20332037.

Skern, T., W. Sommergruber, D. Blaas, P. Gruender, F. Fraundorfer, C. Pieler, I. Fogy, and E. Kuechler. 1985. Human rhinovirus 2: Complete nucleotide sequence and proteolytic processing signals in the capsid. Nucleic Acids Res. 13: $2111-2126$

Skinner, M.A., V.R. Racaniello, G. Dunn, J. Cooper, P.D. Minor, and J.W. Almond. 1989. New model for the secondary structure of the $5^{\prime}$ non-coding RNA of poliovirus is supported by biochemical and genetic data that also show that RNA secondary structure is important in neurovirulence. I. Mol. Biol. 207: 379-392.

Starzyk, R.M., S.W. Koontz, and P. Schimmel. 1982. A covalent adduct between the uracil ring and the active site of an aminoacyl tRNA synthetase. Nature 298: 136-140.

Steitz, J.A. 1975. Ribosome recognition of initiator regions in the RNA bacteriophage genome. In RNA phages (ed. N.D. Zinder), pp. 319-352. Cold Spring Harbor Laboratory, Cold Spring Harbor, New York.

Svitkin, Y.V., S.V. Maslova, and V.I. Agol. 1985. The genomes attenuated and virulent poliovirus strains differ in their in vitro translation efficiencies. Virology 147: 243-252.

Svitkin, Y.V., T.V. Pestova, S.V. Maslova, and V.I. Agol. 1988. Point mutations modify the response of poliovirus RNA to a translation initiation factor: A comparison of neurovirulent and attenuated strains. Virology 166: 394-404.

Trono, D., R. Andino, and D. Baltimore. 1988. An RNA sequence of hundreds of nucleotides at the $5^{\prime}$ end of poliovirus RNA is involved in allowing viral protein synthesis. J. Virol. 62: 2291-2299.

Van der Werf, S., J. Bradley, E. Wimmer, F.W. Studier, and J.J. Dunn. 1986. Synthesis of infectious poliovirus RNA by purified T7 RNA polymerase. Proc. Natl. Acad. Sci. 83: 23302334.

Wimmer, E. 1982. Genome-linked proteins of viruses. Cell 28: 199-201. 


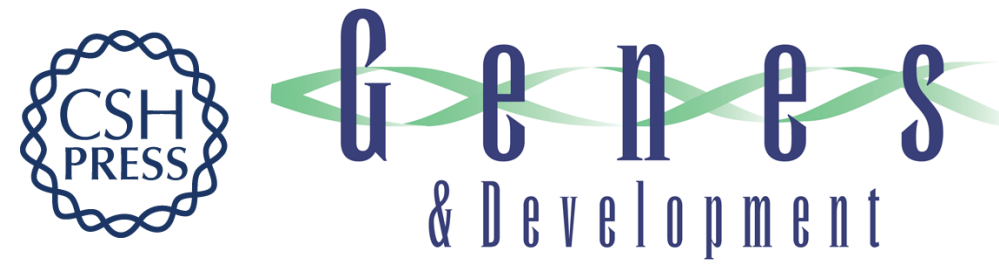

\section{Cap-independent translation of encephalomyocarditis virus RNA: structural elements of the internal ribosomal entry site and involvement of a cellular 57-kD RNA-binding protein.}

S K Jang and E Wimmer

Genes Dev. 1990, 4:

Access the most recent version at doi:10.1101/gad.4.9.1560

References This article cites 45 articles, 22 of which can be accessed free at: http://genesdev.cshlp.org/content/4/9/1560.full.html\#ref-list-1

License

Email Alerting Service

Receive free email alerts when new articles cite this article - sign up in the box at the top right corner of the article or click here.

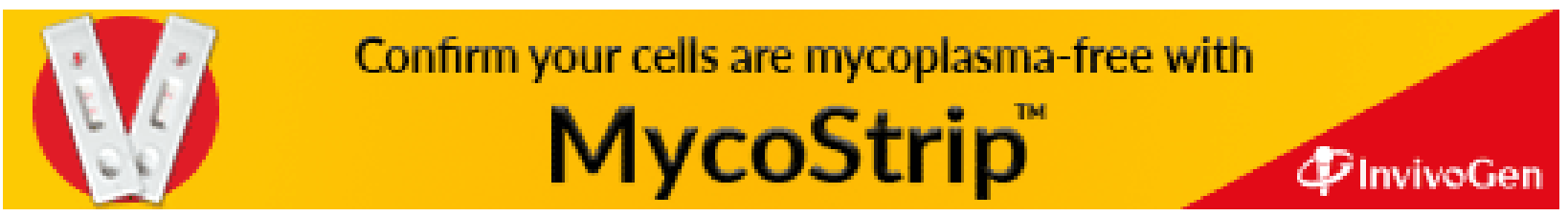

